\title{
NEUROPSYCHOLOGICAL EVALUATION AND COGNITIVE EVOLUTION OF A BILINGUAL ALZHEIMER PATIENT
}

\author{
CARmen Díaz \& Herminia Peraita
}

Facultad de Psicología,Universidad Nacional de Educación a Distancia, Madrid

\begin{abstract}
We present the case of a university-educated bilingual (Italian-Spanish) Alzheimer patient aged 61. After a neuropsychological assessment carried out at the Applied Psychology Service of the Faculty of Psychology at the Universidad Nacional de Educación a Distancia (UNED), an individualized integral cognitive stimulation program was started that lasted three years. The interest of this case lies in the fact that the progress of this patient in the two languages was followed through a series of cognitive tasks (mainly linguistic and categorization). The results show that, as the illness develops, the patient cannot separate both languages and interferences appear. His first language remains intact for a longer period of time, as studies of this type have shown.
\end{abstract}

Keywords: Alzheimer's disease, neuropsychological assessment, bilingualism, semantic knowledge.

Evaluación neuropsicológica y evolución cognitiva de un enfermo de Alzheimer bilingüe

Resumen: Presentamos el caso de un paciente de Alzheimer bilingüe (italiano-español) de 61 años con estudios universitarios. Tras la evaluación neuropsicológica realizada en el Servicio de Psicología Aplicada (SPA) de la Universidad Nacional de Educación a Distancia (UNED), se inició un programa de estimulación cognitiva individualizada que duró tres años. El interés de este caso radica en el hecho de que la evolución del paciente en las dos lenguas fue seguida a través de una serie de tareas cognitivas (principalmente lingüísticas y de categorización). Los resultados muestran que, según avanza la enfermedad, el paciente no puede separar ambas lenguas y ocurren las interferencias. Su primera lengua se conserva durante un mayor periodo de tiempo, como los estudios de este tipo han mostrado.

Palabras clave: Demencia tipo Alzheimer, evaluación neuropsicológica, bilingüismo, conocimiento semántico.

\section{INTRODUCTION}

The scientific basis of non-pharmacological intervention was summarized, albeit metaphorically, by Santiago Ramón y Cajal, who said that we are all capable of being the sculptor of our own brain. This idea is included in the term «neuroplasticity» proposed by Geschwind and Nottebohm (1985), who referred to the brain's capacity to adapt, regulate, and remodel the dy-

Recibido 5 December 2007; accepted 4 July 2008

Correspondencia: Carmen Díaz, UNED, Facultad de Psicología, Dpto. Psicología Básica I, Juan del Rosal, 10, 28040 Madrid, Spain.

Agradecimientos: Este trabajo ha sido posible por la inestimable colaboración de F.P. y su familia. Financiado en parte por los proyectos de invstigación del MEC, SEJ 2004-04233 y SEJ 2007-63325. namics of neurotransmission when faced with adverse conditions, even in old age. This capacity has been demonstrated in cases of dementia, although with lower intensity (Kavirajan and Olazarán, 2005; Orrell, 2003). Therefore, it seems logical to think that cognitive stimulation can favour cerebral plasticity and thus maintain, if not recover, the cognitive functions which have been preserved. An intervention programme should not only promote greater cognitive function, which allows the patient more autonomy for a longer period of time, but it should also improve the patient's self-esteem and feeling of worth.

The study of bilingual individuals with cerebral lesions and the importance of these lesions in the organization of language have been the focus of research during recent years, although this area was already being examined during the first half of the $19^{\text {th }}$ century (Lorch, 2007). 
Few studies examine the linguistic-cognitive function in bilingual Alzheimer's patients in terms of disease progression and the intervention to be adopted. In one of the few studies of this type, De Vreese, Motta, and Toschi (1988) conclude that, in patients suffering from dementia, the comprehension and production of the mother tongue is preserved longer than the comprehension and production of a second or third language, but that cognitive stimulation programmes should be carried out in both languages.

In the production of speech, a bilingual subject uses at least two types of processes and mechanisms: attentional and linguistic. The attentional mechanism deals with the control that the bilingual subject needs to have in order to speak in the language required by the communicative exchange at a given time, without allowing the second language to surface or interfere. It is therefore assumed that bilingual subjects have greater cognitive flexibility than monolingual subjects due to the fact that they regularly change the language they express themselves in. This has brought about the idea that the processes involved in the control of execution are more developed in bilingual subjects than in monolingual subjects. Therefore, in old age, when these processes tend to relax and, consequently, have less control of inhibition, the bilingual subject will, to a certain extent, be protected against a possible impairment in executive control (Byalistock, Craik, Klein, and Viswanathan, 2004). The linguistic processes involved have phonological, lexical, syntactic, and semantic components. The importance of bilingualism as a factor that helps to stabilize cognitive functioning was recently analysed by Byalistock, Craik, and Freedman (2007), who suggest that bilingualism could help to delay the symptoms of dementia for as long as four years.

The variables involved in bilingual speech production include the similarity between the languages and the degree of bilingualism that comes from the level of competence in the second language, depending on when it was learnt. In the first case, it appears that cognate (similar or even identical) rather than non-cognate words e.g. "gallina" in Spanish and "gallina" in Italian, facilitate lexical access. This is seen in the minor errors that occur in naming and oth- er tasks. However, what is not known is exactly why this occurs, although three different theories exist. One alludes to a greater semantic overlap (i.e. the shared semantic features of cognate words), another defends the existence of only one lexical entry shared by both languages, and the third attributes it to a phonological overlap (Byalistock et al. 2004).

The production of speech in bilingual subjects is generally studied through different language tasks and tasks of linguistic interference between drawings and words. The variables that are usually measured are correct answers/errors and the reaction time.

In the present study, which was carried out in the context of a non-specific cognitive intervention programme, we addressed a wide series of cognitive processes in the framework of language interventions, with special emphasis on the lexical-semantic level, because one of the key questions in the linguistic and cognitive area of knowledge of bilingual subjects is whether their conceptual representations are shared between the two languages. In order to answer this question, we designed classification and categorization tasks to verify whether the results were the same in both languages, regardless of the language in which the tasks were carried out.

Given the results of the study by De Vreese et al. (1988), we expected the patient to maintain linguistic competence in the first language for longer than the second, which is the one generally used by the patient, even if more intensive stimulation in Spanish (second language) can reduce the rate at which it is lost. This study is observational and descriptive, although a large number of semi-experimental tasks and neuropsychological tests were used.

Methodological difficulties arise when making inferences from the data of only one subject. Other authors (Crawford, Garthwaite, Azzalini, Howell and Laws, 2006) recently analysed these difficulties and offered methodological solutions, although always with a significantly large control group. In our case-a bilingual Alzheimer's patient — obtaining a control group was not possible for obvious reasons.

The aims of this study were to evaluate the development of the subject's two languages whilst 
his illness progressed, and to monitor the course of the semantic-conceptual knowledge of the subject in relation to the decline in both languages.

\section{METHOD}

\section{Participant}

The patient was a right-handed male aged 61 years old at baseline. He was diagnosed with probable Alzheimer's disease (AD) in October 2001 at the Neurological Department, Hospital Clínico in Madrid, Spain.

\section{Antecedents}

The patient suffered a reactive depression after a conflictive labour situation in 1995 and, consequently, stopped work. He visited his doctor in 1997 because he had experienced episodes of forgetfulness. His wife reported that the real cognitive difficulties began in 1999, since from this point he had episodes of forgetfulness on a daily basis, took little part in conversations, and repeated himself. In July 2001, he underwent complementary neurological tests as a result of the information obtained during the first interview. In October 2001 he was diagnosed with mild AD at the Hospital Clínico, Madrid. He took part in the hospital's AD immunization project from November 2001 until March 2002, when the project was suspended. During this period, he received no treatment whatsoever. The main problems reported by the patient and his wife, from diagnosis until suspension of the immunization project, were difficulties with learning, recent episodic memory, written and verbal comprehension, arithmetic calculation, and space-time orientation.

The patient is Italian, but, since he was a teenager he has lived in Spain, where he obtained a diploma in law and a degree in economics. He was the sales manager of an international company and when his condition was diagnosed he was not working. His two children live at home. He has not experienced behavioural changes and has shown himself to be enthusiastic, sociable, and optimistic from as early as his first interview. He uses Spanish in his daily life with family, neighbours, and friends, but uses Italian when he speaks to his mother (who lives in Madrid), siblings, or Italian friends.

The patient came to the Applied Psychology Service (APS) of the Faculty of Psychology at the UNED in March 2002 to start a psychological intervention programme and he provided the following information (see Table 1, Figure 1, and Figure 2):

Table 1. Information provided by the patient

Year 2000:

Neuropsychological Tests:

- March: in the Barcelona test (Peña Casanova, 1990), his scores fell within the normal range except for deferred text memory and direct and inverse series.

- September: Mini Mental State Examination (MEC) (Lobo, Ezquerra, Gómez, Sala, and Seva, 1979) = 29/35.

Year 2001:

Neuropsychological Tests:

- June: $M E C=26 / 35$, which suggested that the patient was suffering from possible incipient cognitive deterioration (Reisberg GDS scale 3.)

Brain imaging results:

- July: ventricular dilatation in the MRI. SPECT revealed asymmetrical lack of activity in several areas of the cerebral cortex in both hemispheres. Less uptake in nuclei at the base of the right hemisphere than on the contralateral side (see Fig. 1).

- September: SPECT revealed hypoperfusion on both temporal-parietal lobes and, albeit with less intensity, on the frontal lobes. More evident on the right hemisphere. According to the report, these data are indicative of AD (see Fig. 2). 
Figure 1

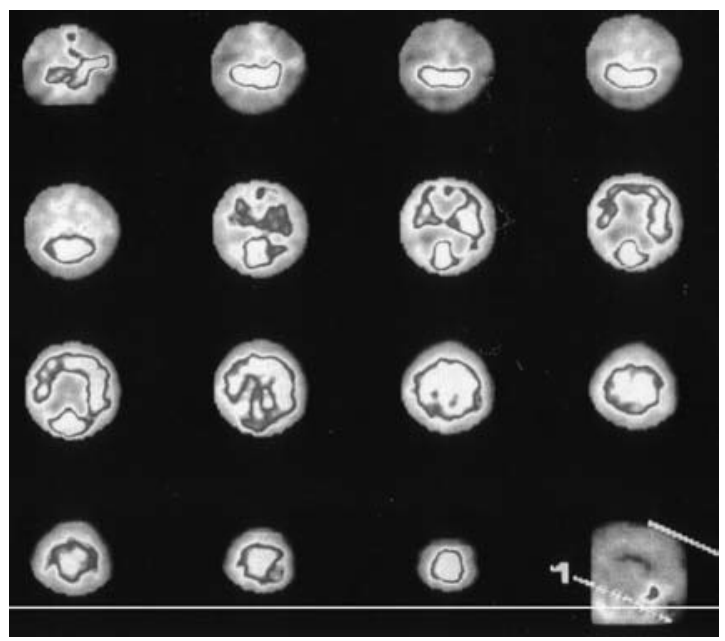

\section{Pharmacological therapy}

In May 2002, the patient began treatment with Reminyl (4 mg) (galantamine), and his dose was increased by the Memory Unit of the Geriatrics Service, Hospital Clínico San Carlos, Madrid, to $12 \mathrm{mg}$ in September 2002. In February 2004, he continued with the prescribed pharmacological treatment, Reminyl, at the same dose and began to take Axura (memantine). He also started treatment with a vitamin complex, Auxina E 400, an anti-platelet drug to prevent cardiovascular diseases, Adiro 100, Ginko Bilova and pravastatin for cholesterol.

\section{Non-pharmacological therapy}

The patient was an irregular attender at group sessions of the Alzheimer's Relatives Association (AFAL) in Madrid. Since January 2004, he has been taking fortnightly sessions of psychomotricity exercises with a therapist geared towards reality orientation in his home. Since February 2005, he has been attending twice-weekly physical activity group sessions coordinated by a therapist.

\section{Neuropsychological assessment}

After the semistructured interview with the patient and his wife, during which the above-
Figure 2

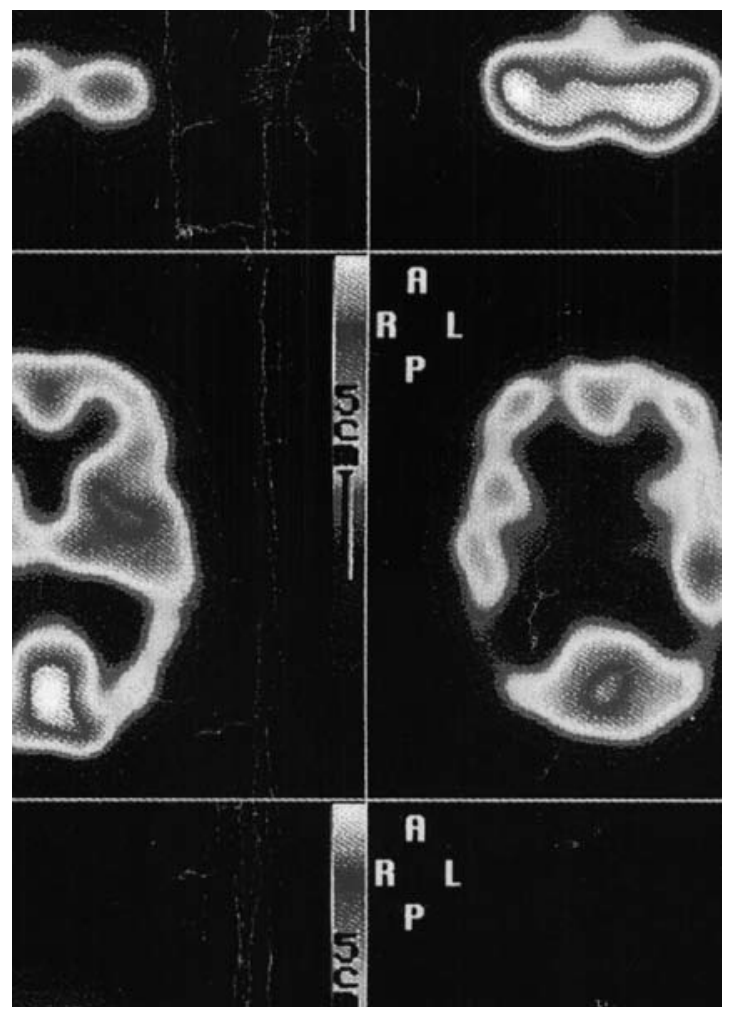

mentioned data were collected, a complete neuropsychological assessment was made over four sessions.

In the first session, the following areas were evaluated: general cognitive state, state of mind, level of dependence in daily activities, and ability to carry out tasks. In the second session, executive function and attentional capacity, episodic and semantic memory, praxic capacity, and level of dementia were tested (see Tables 2 and 3). The third and fourth sessions were dedicated exclusively to the evaluation of the production and comprehension of Spanish and Italian.

Throughout the tests, the patient was happy with his performance and showed neither anxiety nor frustration. At all times, he was collaborative, empathetic, and totally willing to carry out the tests. He does not seem to have been aware of his difficulties. In these sessions, there was no inter-language interference or contamination: he was completely able to keep both 
Table 2. Results of the neuropsychological assessment in the first and second session evaluation

\begin{tabular}{|c|c|}
\hline Test & Results \\
\hline $\begin{array}{l}\text { - Mini Mental State Examination (MEC) (Lobo, Ezquer- } \\
\text { ra,Gómez, Sala, and Seva, 1979). }\end{array}$ & $\begin{array}{l}22 / 35 \\
\text { Scores under } 26 / 27=\text { cognitive deterioration. }\end{array}$ \\
\hline $\begin{array}{l}\text { - Clock Drawing Test (on order) (Cacho, García-García, } \\
\text { Arcaya, Vicente, and Lantada, 1999). }\end{array}$ & $\begin{array}{l}3 / 10 \\
\text { Scores between } 0 \text { and } 6=\text { cognitive deterioration. }\end{array}$ \\
\hline $\begin{array}{l}\text { - Information-Memory-Concentration-Test (Blessed, Tom- } \\
\text { linson, and Roth, 1968). }\end{array}$ & $\begin{array}{l}24 / 37 \\
\text { Cut-off: } 32\end{array}$ \\
\hline $\begin{array}{l}\text { - Depression scale (GDS) (shortened version) (Yesavage } \\
\text { et al. 1983). }\end{array}$ & $\begin{array}{l}0 \\
\text { Cut-off }=5 / 6\end{array}$ \\
\hline $\begin{array}{l}\text { - Blessed Dementia Rating Scale (Blessed, Tomlinson, } \\
\text { Roth, et al. 1968). }\end{array}$ & $\begin{array}{l}5.5 \\
\text { Scores above } 4 \text { points = probable deterioration. }\end{array}$ \\
\hline $\begin{array}{l}\text { - Informer Test (shortened version) (Jorm and Korten, 1988) } \\
\text { Informant Questionnaire on Cognitive Decline in the Eld- } \\
\text { erly (IQCODE), Spanish version (Morales et al. 1992) }\end{array}$ & 59 \\
\hline — Stroop Test (Stroop, 1935) (45 seconds per card). & $\begin{array}{l}\text { Scores above } 57=\text { probable cognitive deterioration. } \\
1 \text { st card, } \mathrm{W}=74 ; 2 \text { nd card, } \mathrm{C}=34 ; 3 \text { rd card, } \mathrm{WC}=12 \text {. } \\
\text { Errors }=0 . \text { Interference: }-8.9 . \text { The means for the Spanish } \\
\text { population are: } \mathrm{W}=113 ; \mathrm{C}=71 ; \mathrm{WC}=43 . \text { Interference }=1.73 \text {. }\end{array}$ \\
\hline — Trail Making Test (CTMT) (Reitan, 1958). & $\begin{array}{l}\text { Version A: Time: 1' 40» } \\
\text { Version B: He did not understand the test. The test was sus- } \\
\text { pended. }\end{array}$ \\
\hline $\begin{array}{l}\text { - Barcelona Test (Peña-Casanova, 1990): (subtests were } \\
\text { selected according to the cognitive function to be eval- } \\
\text { uated). }\end{array}$ & $\begin{array}{l}\text { Subtests in which the patient's performance was below the } \\
30^{\text {th }} \text { percentile (probable deterioration) are shown below in } \\
\text { the Table } 3 \text {. }\end{array}$ \\
\hline $\begin{array}{l}\text { - The Global Deterioration Scale (GDS) (Reisberg, Fer- } \\
\text { ris, de Leon, and Crook, 1982). }\end{array}$ & $\begin{array}{l}\text { Level } 4-(5) \text { Stage }=\text { moderate cognitive deterioration (Scale: } \\
0 \text { to } 7) \text {. }\end{array}$ \\
\hline — Clinical Dementia Rating (CDR) (Hughes et al. 1982). & Level 1 = mild dementia (Scale: 0 to 3 ). \\
\hline
\end{tabular}

Table 3. Subtests of the Barcelona Test with points below the 30 th percentile

Thematic narration

Direct digits

Sentence repetition

Naming of images

Categorical evocation $\langle\mathrm{P}\rangle$

Comprehension written order

Comprehension of sentences and texts

Imitation of bilateral postures

Posture sequences

Reciprocal coordination

Superimposed images

Pairing of faces

Memory of texts

Memory of texts with questions

Deferred memory of texts

Deferred memory of texts with questions

Similarities-abstraction languages separate, made decisions easily, and made no errors whatsoever.

The results of the neuropsychological tests supported the diagnosis of probable AD according to the criteria of the National Institute of Neurological and Communicative Disorders and the Alzheimer's Disease and Related Disorders Association (NINCDS-ADRDA) (McKhann et al. 1984). Similarly, the results of the neuropsychological evaluation lead us to believe that the patient was in the early stages of the disease. The most important results were as follows:

1. Memory and learning and executive function. The patient had difficulties with temporal orientation - he responded correctly to 2 of the 5 items in the temporal orientation section of the MEC (Lobo, Ezquerra, Gómez, Sala, and 
Seva, 1979) and to 3 of the 6 items from the Information-Memory-Concentration test (IMC) (Blessed, Tomlinson, and Roth, 1968). In learning and episodic memory of immediate and deferred facts, the subject responded correctly to 1 of the 3 items in the MEC, 0 of 1 item in the IMC, and 7 of 23 in immediate recall of texts, 5 of 23 in recall of texts with questions, and 6 of 23 from the Barcelona Test in deferred memory with and without questions (see Table 3 ). Difficulties in learning and recall were confirmed by the patient's wife's responses to the Informant Test (Jorm and Korten, 1988). He made mistakes concerning historical events ( 2 of 4 correct answers in the IMC). The Ribot phenomenon-memories are lost inversely to when they are acquired, that is, the memories that are closest in time disappear first, and more remote memories (such as memories from childhood) take longer to disappear-was also observed throughout the evaluation. As far as operative memory was concerned, the patient's performance was below normal and his ability to initiate behaviours, plan and sequence actions, and inhibit inappropriate or interfering behaviour was altered (see Table 2, points awarded in the Stroop and Trail Making tests). In the Clock Drawing Test, he scored 3 out of 10: this indicates not only difficulties in executive function, but also difficulties in semantic and episodic memory, attention, and capacity for abstraction.

2. Language.: The production of spontaneous oral language was evaluated in Spanish and Italian using three subtests of the Barcelona test (PeñaCasanova, 1990): conversation-narration, thematic narration, and description. The patient maintained phonological and syntactic components in both languages. At the lexical level, he produced circumlocutions, confabulations, and repetitions, which were confirmed mainly by the thematic narration test. The joint evaluation of the above tests means that the information content was poor both in Spanish and in Italian. In spontaneous language, his speech was fluent and relevant, but he could not always find the right word in Spanishhe said asiento (chair) instead of mesa (table), vaso (glass) instead of florero (vase) - or in Italian - he said pascolo (meadow) instead of bosco (forest), piattino (plate) instead of possacenere (ashtray). This was corroborated by the naming tests. In the Barcelona test, the subject lies in the lowest zone of the profile: he correctly named $92 \%$ of the items both in Spanish and in Italian. In the Semantic Memory Evaluation Battery (EMSDA) (Peraita, González Labra, Sánchez Bernardos and Galeote, 2000), he correctly named $88 \%$ of the items in Spanish and $97 \%$ of the items in Italian. The results of the tests of reading logatomes, words, and text were normal in both languages (all answers correct). The production of written language as evaluated by dictation tests was unaltered (all answers correct). In oral comprehension analysed using the Barcelona subtests - pointing out pictures and parts of the body and comprehension of verbal orders - his result was within the normal range (all answers correct). Alteration of written comprehension was verified using the subtests of the Barcelona test on comprehension of written orders (he scored 6 out of 12 in Spanish and 7 out of 12 in Italian) and comprehension of phrases and texts (he scored 6 out of 8 in Spanish and 7 out of 8 in Italian).

3. Motor function. The patient found it difficult to carry out movements (apraxia) both unimanually and bimanually. In the subtest imitating right postures, he scored 9 out of 10 (30th percentile), and in the imitation of bilateral postures he scored 6 out of 8 (below the 10th percentile). In the subtest arbitrary right sequences and in reciprocal coordination, he scored 4 out of 8 , but his graphic execution was normal in copying models (all answers correct).

4. Perception, attention, and capacity for abstraction. The patient experienced perceptive discrimination and attention difficulties in several areas of the Barcelona test: discrimination of superimposed images (he scored 16 out of 20 ), face matching (he scored 3 out of 6 ), and alterations in attention capacity and in capacity for abstraction, as shown by the Clock Drawing Test (he scored 3 out of 10). With regard to solving tasks involving logical opinion or capacity for abstraction, he made mistakes in the Barcelona subtest similarities-abstraction ( 0 out of 12 ).

In summary, the areas which the patient preserved within the normal range were reading and 
writing, both when copying and in dictation (all answers correct). Although some mistakes were observed in the semantic memory system, it was less deteriorated than the (recent) episodic system. In fact, in two of the Barcelona subtests that evaluate the semantic system-categorical evocation of animals and completion by denomination (in which the subject should complete sentences where the last word was missing) - the patient had a satisfactory performance for his age and level of education $\left(50^{\text {th }}\right.$ percentile in the first test and $95^{\text {th }}$ percentile in the second).

\section{Intervention sessions and follow-up evaluations}

After obtaining the results of the neuropsychological evaluation, we decided to draw up an intervention programme to help stimulate the different preserved cognitive functions and not only intervene in those where deficits were observed. The final objective was to maintain cognitive skills and/or processes for as long as possible. The intervention programme was integral in that it included activities from each of the cognitive processes: attention, memory, language, executive functions, and praxia. The techniques used were reminiscence, cognitive stimulation therapy, and reality orientation. A detailed explanation of this intervention programme will be provided in a future study.

In order to avoid problems of interference between the two languages, sessions were carried out in Spanish or in Italian, but the languages were never mixed in one session. Every attempt was made to ensure that each session in Spanish was followed by an identical session in Italian. This was not always possible, with the re- sult that the latter were less frequent.

Because our main objective was to ascertain whether the conceptual representations of this bilingual patient were shared, we designed some identical classification tasks to be applied in each language in the corresponding sessions (Díaz and Peraita, 2004; Díaz and Peraita, 2005).

We designed a classification task (shopping basket) to show one of the main functions of the semantic memory system, that is, the capacity of the subject to form groupings, relevant to the logical and/or psychological and/or contextual points of view. The patient was presented with 48 colour photographs representing the shopping basket-24 foods and 24 objects - and he was told to make as many groups of objects as he thought necessary, but to make sure they went well together.

\section{RESULTS}

To illustrate the course of deterioration in this patient, Table 4 shows the results of some of the evaluations over time. Others could not be applied due to the cognitive problems experienced by the patient, mainly in written and oral comprehension.

The shopping basket task was applied in five sessions over the three years in both languages, and the results are summarised in Table 5. The patient's performance in both languages was very similar in all the sessions, as was the percentage of correct answers in the categories of food and objects.

As for control in both languages, at the beginning of the cognitive intervention programme, no differences were detected in the performance

Table 4. Evaluation results of the patient in different tests and at different points in time

\begin{tabular}{llll}
\hline \multicolumn{1}{c}{ Tests } & \multicolumn{1}{c}{ May 2003 } & March 2004 & March 2005 \\
\hline MEC & $22 / 35$ & $16 / 35$ & $12 / 35$ \\
Clock Drawing Test (on order) & - & $2 / 10$ & $2 / 10$ \\
Clock Drawing Test (copy) & - & $9.5 / 10$ & $2 / 10$ \\
Categorical evocation P* & 26 & 27 & 8 \\
Categorical evocation of animals * & 10 & 5 & 6 \\
Naming* & $13 / 14$ & $13 / 14$ & $13 / 14$ \\
Yesavage & 0 & 0 & 0 \\
\hline
\end{tabular}

Note: * Subtest of the Barcelona test 
Table 5. Results in the classification task «Shopping basket» $\mathrm{N}=48$ items ( 24 foods and 24 objects)

\begin{tabular}{lcccc}
\hline \multirow{2}{*}{ Date } & \multicolumn{2}{c}{ Spanish } & \multicolumn{2}{c}{ Italian } \\
\cline { 2 - 5 } & Correct foods & Correct objects & Correct foods & Correct objects \\
\hline October 2002 & $24(100 \%)$ & $24(100 \%)$ & $24(100 \%)$ & $24(100 \%)$ \\
December 2002 & $24(100 \%)$ & $22(91.6 \%)$ & $24(100 \%)$ & $22(91.6 \%)$ \\
April 2003 & $24(100 \%)$ & $19(79.16 \%)$ & $24(100 \%)$ & $20(83.33 \%)$ \\
January 2004 & $18(75 \%)$ & $17(70.83 \%)$ & $20(83.33 \%)$ & $18(75 \%)$ \\
July 2004 & $16(66.66 \%)$ & $15(62.5 \%)$ & $17(70.83 \%)$ & $16(66.66 \%)$ \\
\hline
\end{tabular}

of the activities, regardless of the language used. The patient was competent in both languages during the production of spontaneous speech and content was adequate for the conversational context. As the illness progressed, he changed from one language to another when he was talking to a person, something that did not occur at the beginning. Nevertheless, he managed a certain control of the situation as he only changed from one to another whilst talking to a person who spoke both languages, not only Spanish. His cognitive flexibility was excellent at the beginning of the intervention programme as he was capable of alternating between both languages during oral production. He did this only if the other speaker did the same and was able to speak Spanish only when the interlocutor spoke in Spanish; therefore, he was competent in both the bilingual and monolingual mode. This reveals complex attentional control, i.e. greater capacity in bilinguals to change linguistic code (Byalistock et al. 2004; De Vreese, al. 1988).

Seven months later, we detected the intrusion of some Italian words during the tests in Spanish and vice versa, in particular during the fluency and classification tasks. During the semantic fluency test in Italian, we observed intrusions of words from the second language in the first, such as the word gallina (hen) instead of gallina - these were cognates - corbata (tie) instead of cravatta, and clavel (carnation) instead of garòfano. This had not happened previously or was extremely sporadic. From October 2002, the errors were more obvious in the Spanish tasks because he answered in Italian instead of Spanish. Some of these intrusions were lumaca (snail) instead of caracol, formaggio (cheese) instead of queso, espàndere (spread) instead of untar, pizzico (pinch) instead of piz- ca, puledro (pony) instead potro, garòfano (carnation) instead of clavel, camicia (shirt) instead of camisa, piccolo (little) instead of pequeño. When the intervention programme had finished - it became impossible to get to the center, thus making it necessary to use another type of intervention - the main caregiver, the patient's wife, was extremely positive, in the sense that she was aware that her husband maintained some cognitive and emotional capacities which she had not expected. At this stage, the patient was capable of speaking with an interlocutor, even if the content of his conversation was very poor, and he maintained a connection with his immediate and near environment. The programme has helped him maintain a high level of efficiency, he felt useful, and the working sessions were rewarding for him, despite the effort. Furthermore, he had no important behavioural alterations, except for wandering.

\section{DISCUSSION}

This descriptive study has allowed us to contribute more data to the field of progressive language deterioration in a bilingual (Spanish/Italian) Alzheimer's patient, by means of a follow-up within the framework of a three-year intervention programme. This is particularly interesting, given that there are very few reports on this type of patient in which an evaluation and intervention are made in both languages, a fundamental aspect if we want to determine the real linguistic ability of a person, as pointed out by Fabbro (2001).

Even though no comparable empirical studies exist, the most relevant conclusion for our objectives is that the patient's competence in both 
languages survived with almost no interference during the first three years of the disease. This probably means that the patient sustained attentional control of both languages, and that this control was only inhibited at the end of the third year, as seen through spontaneous conversation and specific tests, such as verbal fluency for semantic categories, description of objects, and classification/categorization tasks.

This decline is particularly significant in terms of the control of the languages in which he is competent, from total control at the level of spontaneous conversation depending on the interlocutor's language, to a gradual loss of this control, not only in spontaneous comprehension, but also in categorization tasks. This loss of attentional control became noticeable through the gradual intrusion of words from the mother tongue into the second language, although this happened much less frequently in the other direction, and through the patient's inability to maintain the linguistic communicative interchange in Spanish with a person who spoke only Spanish. The mother tongue is maintained longer because it is stored using implicit strategies, whereas the second language is stored using explicit strategies (Fabbro, 2002).

The inevitable decline in the patient's cognitive performance as a consequence of dementia observed in the neuropsychological tests and medical evaluations, despite being progressive, has been in some way "controlled». This result agrees with the latest research, which states that non-pharmacological intervention during the mild stages of the disease can slow down the progress of $\mathrm{AD}$ for some years (Kavirajan and Olazarán, 2005).

We believe that the psychostimulation programme carried out in both languages has helped the patient preserve his cognitive capacities and that this, in turn, has helped him maintain his day-to-day autonomy.

\section{REFERENCES}

Blessed, G., Tomlinson, B.E., and Roth, M. (1968). The association between quantitative measures of dementia and senile changes in the cerebral grey matter of elderly subjects. British Journal of Psychiatry, 114, 797-811.
Byalistock E., Craik, F.I.M., Klein, R., and Viswanathan, M. (2004). Bilingualism, aging and cognitive control: Evidence from the Simon Task. Psychology and Aging, 19, 290-303.

Byalistock E., Craik, F.I.M., and Freedman, M. (2007). Bilingualism as a protection against the onset of symptoms of dementia. Neuropsychologia, 45, 459-464.

Cacho, L.J., García-García, R., Arcaya, J., Vicente, J.L., and Lantada, N. (1999). Una propuesta de aplicación y puntuación del test del reloj en la enfermedad de Alzheimer. Revista de Neurología, 28, 7.

Crawford, J.R., Garthwaite, P.H., Azzalini, A., Howell, D.C., and Laws, K.R. (2006). Testing for a deficit in single-case studies: effects of departures from normality. Neuropsychologia, 44, 666-677.

De Vreese, L.P., Motta, M., and Toschi, A. (1988). Compulsive and paradoxical translation behaviour in a case of presenile dementia of the Alzheimer type. Journal of Neurolinguistics, 3, 233-259.

Díaz, C., and Peraita, H. (2004). Deterioration of semantic memory in Alzheimer's disease: natural and object categories. 28th International Congress of Psychology. Beijing (China).

Díaz, C., and Peraita, H. (2005). Cognitive intervention for a bilingual Alzheimer's disease patient. 1st International Consensus Conference. Non Pharmacological Therapies for Alzheimer's. Madrid.

Fabbro, F. (2001). The bilingual brain: bilingual aphasia. Brain and Language, 79, 201-210.

Fabbro, F. (2002). The bilingual brain: cerebral representation of languages. Brain and Language, 79, 211-222.

Filley, C.M., Ramsberger, G., Menn, L., Wu, J., Reid, B.Y., and Reid, A.L. (2006). Primary progressive aphasia in a bilingual woman. Neurocase, 12, 296-299.

Geschwind, N., and Nottebohm, E. (1985). Mechanism of change after brain lesions. Annals of the New York Academy of Sciences, 457, 1-11.

Hudges, C.P., Berg, L., Danziger, W.L., Cohen, L.A. and Martin, R.L. (1982). A new clinical for the staging of dementia. British Journal Psychiatry, 140, 566-72.

Jorm, A.F., and Korten, A.E. (1988). Assessment of cognitive decline in the elderly by informant interview. The British Journal of Psychiatry, 152, 209-213.

Kavirajan, H.C., and Olazarán, J. (2005). Benefits of motor-cognitive intervention in MCI and mild to moderate Alzheimer's disease. Neurology, 65, 338-339.

Lobo A., Ezquerra J., Gómez F., Sala J.M., and Seva A. (1979). El Mini-Examen Cognoscitivo. Un test sencillo, práctico, para detectar alteraciones intelectivas en pacientes médicos. Actas Luso Españolas de Neurolología, Psiquiatría y Ciencias Afines, 3, 189-202.

Lorch, M. (2007). Bilingualism and memory: Early 19th century ideas about the significance of polyglot aphasia. Cortex, 43, 658-666. 
McKhann, G., Drachman, D, Folstein, M., Katzman, R., Price, D., and Stadlan, E.M. (1984). Clinical diagnosis of Alzheimer's disease: report of the NINCDS-ADRDA work group under the auspices of the Department of Health and Human Services Task Force on Alzheimer's disease. Neurology, 34, 939-944.

Morales JM, González-Montalvo JI, Del Ser T., and Bermejo, F. (1992). Validation del S-IQCODE: the Spanishinformant questionnaire on cognitive decline in the elderly. Archives of Neurology, 55, 262-266.

Orrell, M. (2003). Efficacy of an evidence-based Cognitive Stimulation Therapy programme for people with dementia: Randomised controlled trial. British Journal of Psychology, 183, 248-254.

Peláez, E., and Fernández, S. (1999). Intervención con pacientes con enfermedad de Alzheimer: un programa piloto de neuroestimulación. Paper. First International Congress on Neuropsychology in Internet. Retrieved in October 2006 from

www.uninet.edu/union99/congress/libs/reh/rh06.html Peña-Casanova, J. (1990). Programa Integrado de Explo- ración Neuropsicológica. Test Barcelona. Manual. Barcelona: Masson.

Peraita, H., H., González-Labra, M.J., Sánchez Bernardos, M.L., and Galeote, M.A. (2000). Batería de evaluación de la memoria semántica EMSDA, Psicothema, 12, 192-200.

Reisberg, B., Ferris, S.H., de Leon, M.J., and Crook, T. (1982). The Global Deterioration Scale for assessment of primary degenerative dementia. American Journal of Psychiatry, 139, 1136-9

Reitan R. (1958). Validity of the Trail Making Test as an indicator of organic brain damage. Percept Motor Skills, 8, 271-6.

Stroop, JR. (1935). Studies of interference in serial verbal reaction. Journal of Experimental Psychology, 18, 643662.

Yesavage, J.A., Brink, T.L., Rose, T.L., Lum O., Huang, V., Adey, M., and Leirer, V.O. (1983). Development and validation of a geriatric depression screening scale: A preliminary report. Journal of Psychiatry Research, 17, $37-49$. 